\title{
Stromal cell populations in necropsy bone marrow sections from allogeneic marrow recipients and non-transplant patients
}

\author{
S A Dilly, C J Jagger, J P Sloane
}

Abstract

Aims-To compare the numbers of alkaline phosphatase positive reticulum cells (AL-RC) and macrophages in bone marrow transplant (BMT) recipients with numbers in normal subjects and to look for correlations with clinical features.

Methods-Sections of femoral marrow were obtained at necropsy from 18 BMT recipients and nine normal subjects who had died suddenly. AL-RC were visualised through their endogenous alkaline phosphatase activity. Macrophages were stained by an immunocytochemical technique using the antibody EBM/11 (CD68) and through their endogenous acid phosphatase activity. The numbers of stained cells were counted and expressed as a percentage of total nucleated cells.

Results-In both sets of marrow tissue, more macrophages stained for CD68 than for acid phosphatase, indicating macrophage heterogeneity. The percentage value for CD68 positive macrophages was higher among the transplant recipients $(p<0.01)$. At least in part this was caused by a reduction in haemopoietic cell numbers. Percentage values for acid phosphatase and alkaline phosphatase positive cells did not differ between the two groups. To exclude the effect of changes in marrow cellularity, stromal cell ratios were compared. The AL-RC: CD68 and acid phosphatase:CD68 ratios were both lower in BMT recipients, indicating that after BMT either the absolute number of AL-RC and acid phosphatase cells decreases, or CD68 cells increase, or there is a combination of the two. There was no correlation between the number of each cell type and cell dose given at transplantation, time after transplantation, presence of graft versus host disease or infection, marrow erythroid:myeloid ratio, or peripheral white cell count. The ratio of AL-RC to macrophages in our intact marrow was 0.43 , considerably higher than that reported in cultured marrow.

Conclusions-AL-RC and acid phosphatase positive cells may be most important for supporting haemopoiesis and their reduction after BMT may contribute to depression of haemopoiesis. CD68 positive cells include macrophages with a wide variety of functions and these may be increased in response to marrow damage.
( Clin Pathol 1993;46:611-616)

Allogeneic bone marrow transplantation (BMT) for malignant haematological disease is followed by a variable period of pancytopenia. This is a consequence of the treatment required to achieve remission, the pre-transplant conditioning to eliminate host marrow and reduce host immune defences, and the time taken for the donor marrow to proliferate. The clinical problems of graft versus host disease (GvHD) led to ideas of purging donor marrow of $\mathrm{T}$ cells to prevent this complication. Purged marrows, however, were more liable to graft failure, possibly due to the unopposed action of recipient $T$ lymphocytes, and so enhanced pre-transplant conditioning was required. Now interest is focused on the use of growth factors to stimulate haemopoietic recovery after BMT.

In normal bone marrow haemopoietic growth factors are probably produced by some of the marrow stromal cells. Stromal cells consist of a mixture of adipocytes, endothelial cells, fibroblasts, macrophages and "reticular cells". Two cell types seem to be of particular importance. One is a macrophage commonly associated with erythroid precursors and the other is the alkaline phosphatase positive reticulum cell (AL-RC). AL-RC are generally dendritic in shape and closely associated with granulocytic precursors. They synthesise reticular fibres, important for structural support and have adhesion molecules, such as fibronectin, which may be involved in the anchoring of immature cells. Macrophages have many functions in marrow including iron storage, phagocytosis of expelled erythroblast nuclei, and probably production of factors stimulatory to erythrocytes, granulocytes, and macrophages. One hypothesis is that the AL-RC produces a lineage non-specific factor for maintaining early stem cells and also macrophage colony stimulating factor. The macrophage itself would then produce terminal differentiating hormones. ${ }^{1}$

Theoretically, if marrow stroma were damaged then marrow engraftment might be delayed or depressed. Views differ on whether marrow stromal damage is a significant factor in haemopoietic recovery after BMT. In whole-animal experiments in which marrow transplants were given to irradiated mice, there was no evidence of irradiation induced stromal injury. ${ }^{2}$ Marrow cultures grown from patients, three weeks to 10 months after 
Patient details and marrow cell staining

\begin{tabular}{|c|c|c|c|c|c|c|c|}
\hline \multicolumn{8}{|c|}{ Clinical details } \\
\hline $\begin{array}{l}\text { Case } \\
\text { No }\end{array}$ & $\begin{array}{l}\text { Age } \\
\text { (years) }\end{array}$ & Sex & Diagnosis & $\begin{array}{l}\text { Haplotype } \\
\text { match }\end{array}$ & $\begin{array}{l}\text { State at } \\
\text { transplantation }\end{array}$ & $\begin{array}{l}\text { Pre-transplant } \\
\text { conditioning }\end{array}$ & $\begin{array}{l}\text { Days after } \\
\text { transplantation }\end{array}$ \\
\hline 1 & 32 & $\mathrm{~F}$ & AML & 2 & remission 2 & CI & 20 \\
\hline 14 & 33 & M & AML & 2 & remission 1 & CM & 51 \\
\hline 3 & 28 & $\mathrm{M}$ & AML & 2 & remission 1 & MI & 105 \\
\hline 4 & 19 & $M$ & AML & 1 & remission 2 & $\mathrm{CI}$ & 22 \\
\hline 5 & 36 & $\mathrm{~F}$ & AML & 2 & remission 1 & MI & 54 \\
\hline 6 & 47 & $\mathbf{F}$ & CGL & 2 & active & $\mathrm{C}$ & 90 \\
\hline 7 & 7 & $\mathrm{~F}$ & ALL & 2 & remission 3 & $\mathrm{CM}$ & 46 \\
\hline 8 & 14 & $\mathbf{M}$ & AML & 1 & remission 1 & CI & 53 \\
\hline 9 & 20 & $\mathrm{~F}$ & AML & 1 & remission 2 & CI & 140 \\
\hline 10 & 18 & $\mathbf{M}$ & ALL & 1 & remission 2 & $\mathrm{CI}$ & 43 \\
\hline 11 & 39 & $\mathrm{~F}$ & AML & 1 & remission 1 & CI & 14 \\
\hline 12 & 40 & $\mathrm{~F}$ & AML & 2 & remission 1 & CI & 68 \\
\hline 13 & 7 & $\mathbf{M}$ & ALL & 1 & remission 2 & CI & 19 \\
\hline 15 & 19 & $\mathrm{~F}$ & AML & 1 & remission 2 & CI & 56 \\
\hline 16 & 18 & $\mathbf{M}$ & AML & 2 & remission 1 & MI & 7 \\
\hline 17 & 32 & $\mathrm{~F}$ & AML & 2 & remission 1 & $\mathrm{CI}$ & 86 \\
\hline 18 & 29 & $\mathrm{~F}$ & ALL & 2 & remission 2 & CI & 326 \\
\hline 19 & 5 & $\mathrm{~F}$ & AUL & $\overline{1}$ & remission 2 & CI & 22 \\
\hline
\end{tabular}

ALL, acute lymphoblastic leukaemia; AML, acute myeloid leukaemia; AUL, Acute undifferentiated leukaemia; CGL, chronic granulocytic leukaemia. B, bacterial; F, fungal; V, viral (tissue diagnosis); H, haemorrhage; $\mathrm{O}$, acute haemorrhagic pulmonary edema; P, interstitial pneumonitis; T, thrombosis. C, cyclophosphamide (two doses of $60 \mathrm{mg} / \mathrm{kg}$ body weight); I; total body irradiation ( $(9.5 \mathrm{~Gy}$ at $0.025 \mathrm{~Gy} / \mathrm{min}) ; \mathbf{M}$, melphalan $\left(240 \mathrm{mg} / \mathrm{m}^{2}\right)$. Cyclosporin A was used for prophylaxis of GVHD in all cases $(12.5 \mathrm{mg} / \mathrm{kg}$ body weight/day).

BMT, however, did show decreased haemopoietic accessory cell function. ${ }^{3}$ This damage seemed to affect the $\mathrm{Fc}^{+}$and $\mathrm{T}$ cells, which are non-adherent under culture conditions, with roughly normal growth factor production by adherent cells.

\section{Methods}

Upper femoral marrow was obtained at necropsy from 18 marrow recipients and nine non-transplant subjects who died suddenly. All tissues were taken within 24 hours of death. Some was formalin fixed for paraffin wax embedding and some was mounted on cork in OCT compound and snap frozen in isopentane and liquid nitrogen.

Paraffin wax sections were cut at $3 \mu \mathrm{m}$ and stained with haematoxylin and eosin and for chloroacetate esterase and reticulin. Frozen sections were used for staining for endogenous alkaline phosphatase, endogenous acid phosphatase, and with an antibody against macrophages, detecting CD68, EBM/11 (Dakopatts), ${ }^{4}$ and anti-factor VIII related antigen (Dakopatts). Frozen sections were cut at $6 \mu \mathrm{m}$, mounted on multispot slides, air-dried for 1 to 2 hours, fixed in acetone for 25 minutes, rinsed in TRIS-buffered saline (TBS), $\mathrm{pH} 7 \cdot 6$, further fixed in paraformaldehyde-periodate-lysine solution at $4^{\circ} \mathrm{C}$ for 4 minutes and rinsed in TBS. For demonstration of endogenous alkaline phosphatase, the sections were then incubated in substrate using the substituted naphthol method with napthol-ASBI-phosphate and Fast Red TR for 20 minutes. For acid phosphatase, the pararosanolin hydrochloric acid method at pH4.8 was used. After rinsing in distilled water and counterstaining with Mayer's haematoxylin they were mounted in Apathy's medium. For immunocytochemical staining with $\mathrm{EBM} / 11$, primary antibody was applied for 1 hour, followed by goat anti-mouse secondary antibody $\left(\mathrm{F}(\mathrm{ab})^{2}\right.$ (Sigma)) for 30 minutes, alkaline phosphatase antialkaline phosphatase (Dako) for 30 minutes, and then substrate as above, but including Levamisole to block endogenous activity. For antibody against factor VIII related antigen, alkaline phosphatase labelled secondary antibody was used (goat anti-rabbit whole molecule; Sigma). All antisera were diluted in $3 \%$ bovine serum albumin in TBS at $\mathrm{pH} 7 \cdot 6$; secondary antibody had $1 \%$ normal human serum added, and all procedures were at room temperature unless otherwise stated.

The number of stained cells was counted relative to the number of nucleated cells, about 1000 nucleated cells being counted in each case. For statistical analysis, the Wilcoxon rank sum test and Spearman's rank correlation test for non-parametric data were used.

Marrow cellularity was judged by eye on the frozen section material and use to rank the marrows in order of cellularity.

All patients received marrow from family members. Patient details are given in the table. The non-transplanted subjects had a median age of 72 years (range 35-80 years) and comprised six men and three women.

Most BMT recipients were being treated for AML (12/18). Five (cases 14-17 and 19) received marrow that had been purged with CAMPATH 1 or UCHT 1 to remove immune cells in an attempt to reduce GvHD. The overall survival after transplantation varied from seven to 326 days. In 12 cases the survival was greater than six weeks.

\section{Results}

NORMAL FEMORAL MARROW

The marrows had a normal histological appearance with haemopoietic colonies containing a mixed population of erythroid cells, megakaryocytes, and granulocytes at different stages of maturation. The erythroid:myeloid ratio varied from 0.6 to 3.0 (median $=1.3$ ).

Histochemical staining for endogenous alkaline phosphatase showed osteoblasts, 


\begin{tabular}{|c|c|c|c|c|c|c|c|c|}
\hline \multicolumn{3}{|c|}{ Necropsy findings } & \multicolumn{6}{|c|}{ Marrow cells } \\
\hline$G v H D$ & Infections & Other & $C D 68$ & $\begin{array}{l}\text { Acid } \\
\text { phosphatase }\end{array}$ & $\begin{array}{l}\text { Alkaline } \\
\text { phosphatase }\end{array}$ & $\begin{array}{l}\text { Erythroid:myeloid } \\
\text { ratio }\end{array}$ & $\begin{array}{l}\text { Pyknotic } \\
\text { cells }\end{array}$ & $\begin{array}{l}\text { Cellularity } \\
\text { ranking }\end{array}$ \\
\hline - & & $\mathbf{P}$ & 25 & $6 \cdot 6$ & 3.5 & 0.9 & ++++ & 14 \\
\hline+ & & OPT & 26 & $8 \cdot 6$ & $2 \cdot 4$ & 0.13 & + & 12 \\
\hline+ & Fungal & $\mathrm{T}$ & 42 & & $14 \cdot 4$ & $1 \cdot 0$ & +++ & 5 \\
\hline+ & & HT & 31 & $11 \cdot 5$ & $4 \cdot 5$ & $1 \cdot 3$ & + & 6 \\
\hline+ & Viral, Fungal & $\mathrm{T}$ & 38 & & $9 \cdot 2$ & 0.5 & - & 8 \\
\hline+ & Viral & & 20 & $6 \cdot 0$ & $0 \cdot \overline{2}$ & $1 \cdot 7$ & + & 17 \\
\hline - & Bacterial, Fungal, Viral & & 67 & & $9 \cdot 6$ & no haemopoietic activity & - & 2 \\
\hline+ & & & 48 & & $7 \cdot 7$ & 1.5 & +++++ & 13 \\
\hline+ & & $\mathbf{O}$ & 18 & $5 \cdot 0$ & $2 \cdot 6$ & $1 \cdot 3$ & ++++ & 15 \\
\hline+ & & $\mathbf{H}$ & 30 & & $5 \cdot 1$ & 0.4 & + & 18 \\
\hline+ & Fungal & $\mathrm{T}$ & 20 & & $10 \cdot 4$ & $1 \cdot 2$ & +++ & 4 \\
\hline+ & Fungal, Viral & PT & 10 & $3 \cdot 5$ & $2 \cdot 0$ & $0 . \overline{9}$ & ++ & 16 \\
\hline - & & PH & 28 & $10 \cdot 5$ & $11 \cdot 6$ & $0 \cdot 1$ & - & 11 \\
\hline+ & Viral & $\mathrm{H}$ & 50 & $12 \cdot 6$ & 10.6 & $1 \cdot 4$ & ++++ & 3 \\
\hline - & & $\mathrm{T}$ & 42 & $8 \cdot 6$ & $5 \cdot 0$ & $0 \cdot 8$ & +++ & 9 \\
\hline - & Viral & $\mathbf{P}$ & 33 & $7 \cdot 9$ & $4 \cdot 5$ & $1 \cdot 8$ & ++ & 10 \\
\hline - & Fungal & & 35 & & $10 \cdot 2$ & $2 \cdot 2$ & +++++ & 7 \\
\hline - & Fungal & & 38 & $11 \cdot 8$ & $12 \cdot 4$ & no haemopoietic activity & - & 1 \\
\hline
\end{tabular}

endothelial cells, some spindle cells, occasional adipocytes and dendritic cells. The dendritic cells (AL-RC) were generally concentrated in haemopoietic islands and near small blood vessels and did not show any clustering in the paratrabecular areas. Rounded or spindle-shaped alkaline phosphatase positive profiles were present between adipocytes in areas without haemopoietic activity. These cells stained for factor VIII related antigen and so were the endothelial cells of small vessels. Factor VIII related antigen staining was also present on the endothelium of large blood vessels and on megakaryocytes but not on any dendritic-shaped cells.

Immunocytochemical staining using EBM/ 11 and enzyme histochemical staining for acid phosphatase were used to demonstrate the presence of macrophages. These both stained the cytoplasm of macrophages and osteoclasts. The macrophages were numerous, fairly uniformly distributed throughout the marrow, and showed no clear association with any type of haemopoiesis or anatomical compartment (fig 5).

The number of macrophages and AL-RC were counted for each marrow and expressed as a percentage of the cells present. CD68 positive macrophages accounted for $13.5 \%$ (median) of nucleated cells (range 9-21\%), while acid phosphatase positive macrophage numbers had a median value of $8.0 \%$ and ranged from $6 \cdot 7 \%-20 \%$. This difference was significant $(p<0.05)$. The median value for alkaline phosphatase positive cells with dendritic morphology was $5 \cdot 6 \%$ (range $=4 \cdot 6 \%$ $7 \cdot 3 \%$ ). The ratio of AL-RC to CD68 positive cells was $0 \cdot 7$ (range $=0 \cdot 27-1 \cdot 1)$.

FEMORAL MARROW AFTER BMT

After BMT, most marrows were noticeably hypocellular with only three marrow samples having a cellularity comparable with that of the normal group. The marrow stroma showed a variety of appearances which did not correlate with any of the clinical features. Five cases exhibited sinus ectasia, seven had interstitial haemorrhage, five had an increase in fibrous tissue and 14 contained pyknotic cells-in eight cases these were numerous. The pyknotic cells were generally found in areas of erythroid activity and possibly represented either ineffective erythropoiesis or local cell damage. Their numbers did not correlate with clinical features or stromal cell numbers. Adipocytes generally had normal morphological appearances, but in three marrows there were large numbers of small multivacuolated adipocytes. The haemopoietic areas contained cells principally of one lineage in eight cases, and a mixed population in nine cases.

No difference was detected in the distribution of haemopoietic activity between paratrabecular and intertrabecular areas. The erythroid:myeloid ratio varied between 0.13 and $1 \cdot 85$, with a median value of $1 \cdot 16$, which was not significantly different from the value in normal subjects. All of the aforementioned features were compared with cell dose given at transplantation, days after transplantation, presence of GvHD, presence of infection, days to reach a peripheral blood granulocyte count of $0.5 \times 10^{9} 1$ and marrow cellularity. No correlation was detected.

Macrophages accounted for $32 \%$ (range = $10 \%-67 \%$ ) by CD68 staining and $8 \cdot 6 \%$ (range $=3 \cdot 5 \%-12 \cdot 6 \%$ ) by acid phosphatase staining. The number of macrophages staining for CD68 was significantly higher than the number staining with acid phosphatase $(p<0.01)$, and this difference was more pronounced than in the normal marrows. The median number of AL-RC was $6.4 \%$ (range $=0 \cdot 2 \%-14 \cdot 4 \%$ ). Both AL-RC and macrophages were scattered randomly throughout the marrow and were not concentrated in areas of haemopoietic activity (figs 3 and 4). No difference was detected in cell numbers or clinical features in patients receiving purged rather than intact marrow. 

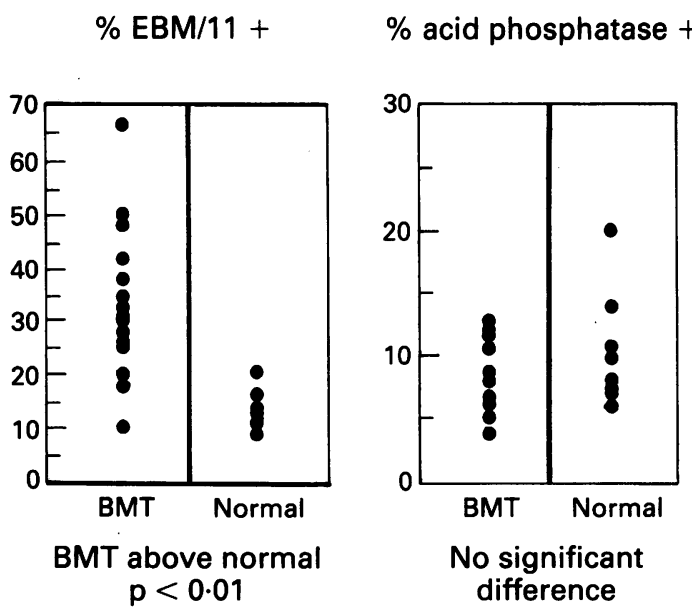

$\%$ alkaline phosphatase reticulum cells

Figure 1 Stromal cell percentage values in patients after BMT compared with nontransplant subjects.
Figure 2 Stromal cell percentage values compared with marrow cellularity.
If the number of each cell type after BMT was compared with the value in normal subjects (fig 1), CD68 positive macrophage numbers were increased $(p<0.01)$ after BMT; acid phosphatase positive cells and AL-RC numbers were not significantly different. After BMT there was an inverse correlation between marrow cellularity and the number of AL-RC or macrophages, whether identified by CD68 or acid phosphatase (fig 2). This partially relates to having to assess
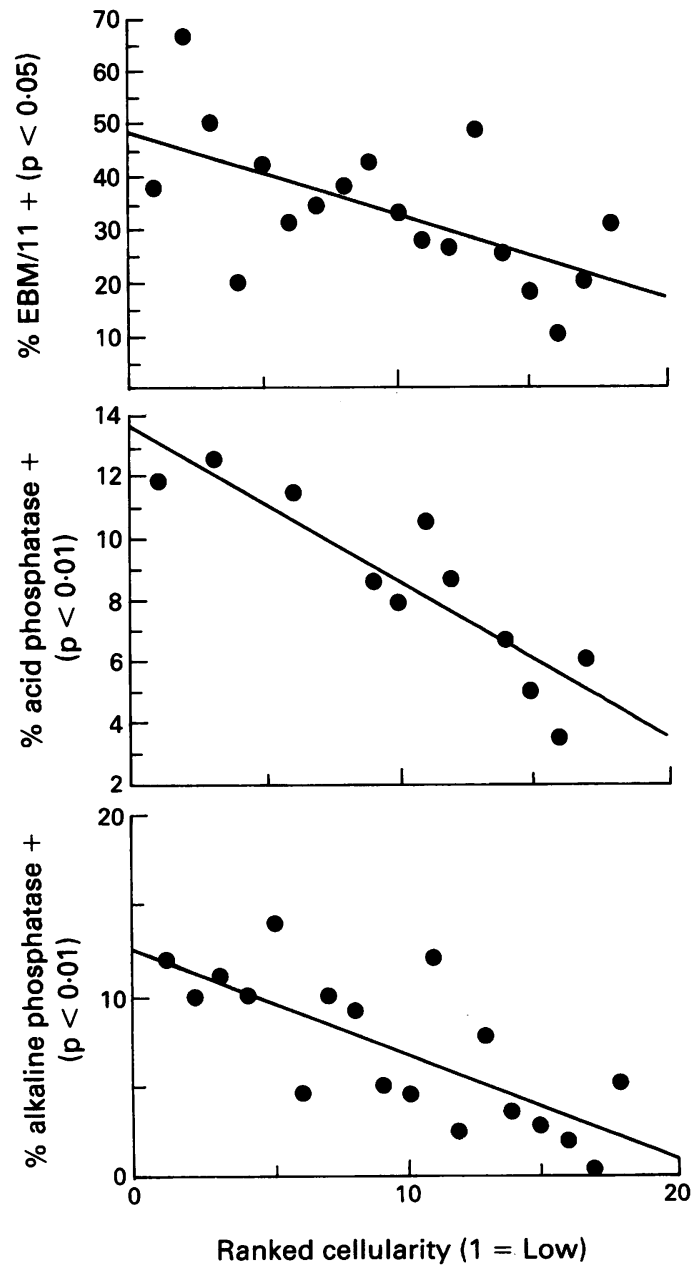

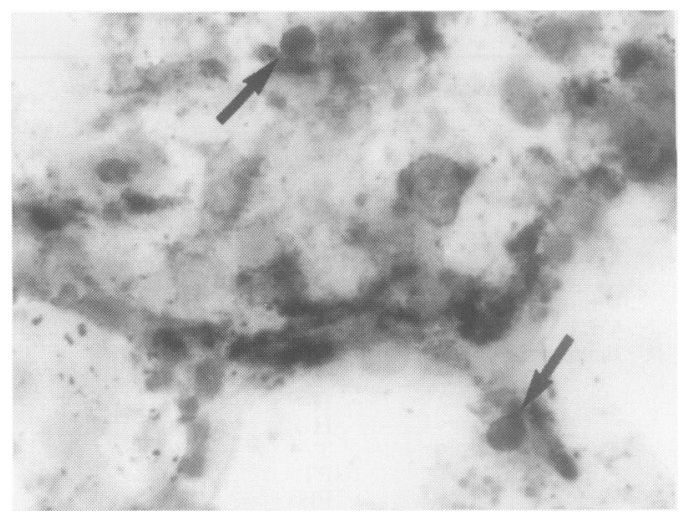

Figure 3 Alkaline phosphatase positive cells in a BMT recipient (arrows indicate increased iron stores).

stromal cell numbers as a percentage of the total nucleated cell population. Thus if stromal cell numbers per unit area remained constant, the percentage value would increase with any drop in haemopoietic cell numbers. Any decrease in haemopoietic elements, however, would affect the percentage value of each stromal cell type equally. Therefore, any ratio of two stromal cell types would cancel out the effect of changes in cellularity and permit an accurate comparison of transplant and non-transplant marrows.

The ratio values for acid phosphatase positive cells: CD68 positive cells, alkaline phosphatase positive cells: CD68 positive cells, and alkaline phosphatase positive cells:acid phosphatase positive cells were calculated for both BMT and non-BMT groups. When the BMT group was compared with the non-BMT group, the acid phosphatase cells:CD68 cells ratio was lower in BMT patients $(\mathrm{p}<0.01)$, the alkaline phosphatase positive cells: $\mathrm{CD} 68$ positive cells ratio was also lower in BMT patients $(<0.01)$, and the alkaline phosphatase positive cells:acid phosphatase positive cells ratio was similar in the two groups. This means that after BMT either acid phosphatase and alkaline phosphatase positive cells decrease in number or CD68 positive cells increase, or a combination of the two changes occurs.

Only three BMT marrows had a

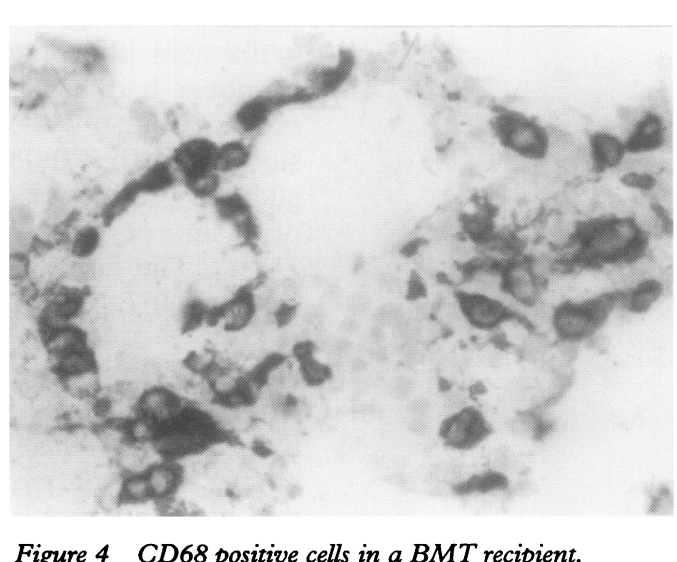


Figure 5 Acid phosphatase positive cells in a non-transplant subject who had died suddenly.

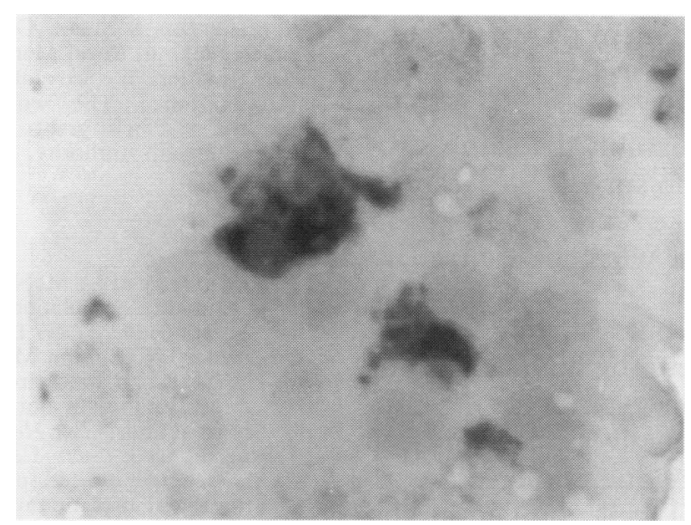

haemopoietic cellularity comparable with that of the normal cases on which to try to answer this question. For CD68 positive cells, two of the BMT cases fell within the normal range while one was higher than normal. For alkaline phosphatase positive cells, one BMT case just reached normal values with the other two cases considerably lower. Acid phosphatase positive cells in the BMT cases were also either lower than the normal range or at the bottom end of it. Therefore, our results suggest a combination of a rise in absolute numbers of CD68 positive cells and a decrease in the other two stromal cell types. It is tempting to postulate that AL-RC and acid phosphatase cells are most important for supporting haemopoiesis and that their reduction after BMT contributes to depression of haemopoiesis, while CD68 positive cells include macrophages with a wide variety of functions, and that these are increased in response to marrow damage.

\section{Discussion}

This study shows that bone marrow stromal cell changes after marrow transplantation differ from those seen in marrow haemopoietic and lymphoid cells.

An interesting discovery was the difference in AL-RC:CD68 ratio $(0.35-0.52)$ in our study, using intact normal human marrow, compared with the ratio found in long term bone marrow cultures (LTBMC). In LTBMC without high dose irradiation, the proportion of each stromal cell type varies between cultures established from different cell suspensions, but generally is around 60-90\% macrophage-like, with the remainder being "large undefined cells", $62 \%$ of which are alkaline phosphatase positive. ${ }^{5}$ This would give an AL-RC:CD68 ratio of $(0.06-0.24)$ which is considerably less than we found in intact marrow. This may well reflect a difference in the suitability of the culture conditions for the two cell types.

It might be predicted that the stroma would show the combined effects of the underlying disease, the treatment required to achieve leukaemic remission, the pre-transplant conditioning agents, and any posttransplant problems, such as GvHD.

The underlying disease of most of these patients was acute myeloid leukaemia (AML). Previous work, using the same staining techniques, has shown that the number of bone marrow macrophages seems to be normal while AL-RC numbers are increased in patients with untreated AML. ${ }^{6}$ LTBMC evidence from patients treated for AML with the "Bart's III" induction regimen and consolidation chemotherapy of thioguanine and cyclophosphamide but no BMT, indicates abnormalities of the stromal cells. ${ }^{7}$ Patients in unmaintained complete remission, who had received no chemotherapy in the preceding five years, showed impaired granulocytemacrophage progenitor cell generation associated with a failure of the stromal cell cultures to grow to confluence (colony stimulating factors were not studied). Most patients in our study received transplantations in first remission for AML and so are clinically similar to the patients studied by Chang, ${ }^{7}$ although they had received chemotherapy within the previous five years. Other work on LTBMC-adherent cells ${ }^{8}$ showed high resistance to methotrexate. At drug levels which reduced myelopoiesis, adherent cells proliferated and continued to produce colony stimulating activity. Only at exceptionally high levels $\left(10^{-3} \mathrm{M}\right)$ did the adherent cell layer fail to support the growth of fresh haemopoietic cells (in vivo toxic plasma concentrations of methotrexate are about $10^{-8} \mathrm{M}$ ).

Radiation is frequently used as part of the pre-transplant conditioning and it is known from the large volume of work on LTBMC that stromal cells show greater radioresistance than haemopoietic and lymphoid cells. In culture a small percentage (less than $5 \%$ ) can survive extremely high doses of irradiation (500 Gy) and still produce haemopoietic growth factors. ${ }^{9}$ The adherent cells after this treatment are a heterogeneous population with two cell types predominating: "a macrophage-like cell and a large flat cell . . . a 'blanket' cell". Most show characteristics typical of macrophages (56\% phagocytic, $85 \%$ acid phosphatase positive, $65 \%$ non-specific esterase positive), with $4 \%$ alkaline phosphatase positive and $0 \%$ factor VIII related antigen positive. If these data are compared with those of Kincade et al, ${ }^{5}$ high dose irradiation does not seem to have a significant qualitative effect on the in vitro adherent cell population.

Much less is known about the in vivo effects of clinical treatment. Stromal damage, including oedema, fibrosis, and the formation of granulomata, has been noted early after $B M T^{1011}$ and following treatment for leukaemia. ${ }^{1213}$ In mice receiving marrow transplants (parent to F1 hybrid), GvHD has been implicated in the stromal damage. ${ }^{14}$ None of these studies, however, has investigated the stromal cell types believed to be important for haemopoiesis. In our study stromal changes, such as sinus ectasia, interstitial haemorrhage, increased fibrous tissue, multivacuolated adipocytes, and increased pyknotic cells, were apparent after BMT but did not correlate with any clinical features. 
An important point to remember when interpreting our work is that it relies on necropsy material and it is possible that patients who die after BMT do not exhibit the same stromal changes as those who survive.

The macrophage-like and AL-RC cells described in the present work are equivalent to cells present in the adherent layer in LTBMC and seem to be relatively undamaged by radiation, chemotherapy, and bone marrow transplantation. Normal haemopoiesis, however, also involves accessory cell function from the non-adherent layer. This seems to reside in the $T$ cell population and on $\mathrm{Fc}$ receptor positive marrow cells, which may represent a subset of natural killer cells. ${ }^{3}$ Previous work on the same group of patients used in this study has documented the number of immune cells using a wide variety of antisera. The numbers of marrow $T$ and $B$ lymphocytes were reduced after BMT, while the number of natural killer cells detected by the antibody HNK1 did not change. ${ }^{15}$ Thus any haemopoietic stimulatory function residing in $T$ cells would be predicted to be impaired in these patients.

Therefore, depressed haemopoiesis after BMT seems to reflect problems with the incoming haemopoietic cells which may be exacerbated by reduction in the accessory function normally provided by $\mathrm{T}$ lymphocytes and AL-RC. Total macrophage numbers are not reduced, but there may be a reduction in certain subtypes, such as that detected by acid phosphatase, which could be a subtype particularly relevant for supporting haemopoiesis. It must be remembered that even if the numbers of macrophages are normal, their interaction with donor stem cells may be influenced by histocompatibility differences and so be impaired early after transplantation, when many macrophages may be of host origin.
We thank Mrs S Milan, Dr R Powles, and the staff of the Leukaemic Unit, Royal Marsden Hospital, for access to clinical information. We are grateful to Mrs V Emmons for secretarial assistance. This work was supported by a locally tarial assistance. This work was supported by a locally organised research grant
Regional Health Authority.

1 Quesenberry PJ, McNiece IK, Robinson BE, et al. Stromal cell regulation of lymphoid and myeloid differentiation. Blood Cells 1987;13:137-46.

2 Gardner RV, Clinton MA, Harrison DE. The decrease in long-term marrow repopulating capacity seen after transplantation is not the result of irradiation-induced stromal injury. Exp Hematol 1988;16:49-54.

3 Emerson SG, Sieff CA, Gross RG, et al. Decreased haemopoietic accessory cell function following bone marrow transplantation. Exp Hematol 1987;15:1013-21.

4 Kelly PMA, Bliss E, Morton JA, Burns J, McGee JO'D. Monoclonal antibody EMB11: high cellular specificity for human macrophages. $\mathcal{F}$ Clin Pathol 1988;41:510-5.

5 Kincade PW, Witte PL, Landreth KS. Stromal cell and factor dependent B lymphopoiesis in culture. Curr Topics Microbiol Immunol 1987;135:1-21.

6 Dilly SA, Jagger CJ. Bone marrow stromal cell changes in haematological malignancies. F Clin Pathol 1990;43: 942-7.

7 Chang I, Geary CG, Testa NG. Long-term bone marrow damage after chemotherapy for acute myeloid leukaemia does not improve with time. $B r \mathcal{F}$ Haematol 1990;75: 68-72.

8 Williams LH, Kodetthoor BU, Lipschitz DA. Long-term bone marrow culture as a model for host toxicity: the effect of methotrexate on hematopoiesis and adherent layer function. Exp Hematol 1988;16:80-7.

9 Gualtieri RJ. Consequences of extremely high doses of irradiation on bone marrow stromal cells and the release of hematopoietic growth factors. Exp Hematol 1987; 15:952-7.

10 van den Berg H, Kluin PM, Zwaan FE, Vossen JM. Histopathology of bone marrow reconstitution after allogeneic bone marrow transplantation. Histopathology 989;15:363-73.

11 van den Berg H, Kluin PM, Vossen JM. Early reconstitution of haematopoiesis after allogeneic bone marrow transplantation: a prospective histopathological study of bone marrow biopsy specimens. F Clin Pathol 1990;43: 365-9.

12 Islam A, Catovosky D, Goldman JM, Galton DAG. Bone marrow fibre content in acute myeloid leukaemia before and after treatment. $\mathcal{F}$ Clin Pathol 1984;37:1259-63.

13 Brody JP, Krause JR, Penchausky L. Bone marrow response to chemotherapy in acute lymphocytic response to chemotherapy in acute lymphocytic 7 Haematol 1985;35:240-5.

14 Hirabayashi N. Studies of graft versus host $(\mathrm{GvH})$ reactions. I. Impairment of hemopoietic stroma in mice suffering from $\mathrm{GvH}$ disease. Exp Hematol 1981;9:101-10.

15 Dilly SA, Jagger CJ, Sloane JP. Lymphocyte populations in autopsy bone marrow sections from recipients of allogeneic marrow and non-transplant sudden death cases. Clin Exp Immunol 1990;81:127-31. 